\title{
Sucrose Fermentation by Proteus hauseri
}

\author{
By J. N. COETZEE \\ Department of Microbiology, University of Pretoria, Pretoria, South Africa
}

(Received 28 December 1961)

\begin{abstract}
SUMMARY
Sixty-three wild strains of Proteus mirabilis were investigated. All 55 strains comprising groups $1 a$ and $1 b$ were found to be cryptic with regard to sucrose fermentation; they possessed competent enzyme systems but did not normally ferment the sugar. No enzyme capable of cleaving this sugar was extracted from the 3 strains of group 2 and the 5 strains belonging to group 3. Partially purified enzyme preparations from two strains of $\boldsymbol{P}$. vulgaris and two cryptic $\boldsymbol{P}$. mirabilis strains were investigated; all four were constitutive $\beta$-D-fructofuranosidases capable of splitting raffinose to melibiose and fructose. Sucrose uptake studies showed that strains of groups $1 a, 1 b$ and 2 did not accumulate sucrose from $1 \%(\mathrm{w} / \mathrm{v})$ solution; the strains of group 3 accumulated large amounts of sucrose. None of the $\boldsymbol{P}$. mirabilis strains was permeable to maltose. The permeability barrier for sucrose was overcome by increasing its concentration to $5 \%(\mathrm{w} / \mathrm{v})$. Under these conditions groups $1 a$ and $1 b$ strains fermented sucrose in peptone water within $36 \mathrm{hr}$. Sodium deoxycholate also changed the permeability barrier of some of the cryptic strains, enabling them to ferment $1 \%(\mathrm{w} / \mathrm{v})$ sucrose promptly. After 3-11 days in $1 \%(\mathrm{w} / \mathrm{v})$ sucrose peptone water all $\mathbf{5 5}$ cryptic $\boldsymbol{P}$. mirabilis, as well as the strains of group $\mathbf{3}$ fermented sucrose. This fermentation was not caused by wild-type organisms, but resulted from the selection of sucrose-positive mutants which arose from the former and were capable of prompt sucrose fermentation. The mutants of strains of group 3 arose at lower rates than those from the cryptic strains. It is concluded that selective permeability to sucrose and $\beta$-D-fructofuranosidase activity are genetically distinct properties of Proteus. A scheme for the classification of phenotypes of $\boldsymbol{P}$. hauseri is presented.
\end{abstract}

\section{INTRODUCTION}

Proteus hauseri (Kauffmann, 1951) consists of two types of organisms which differ in a number of biochemical reactions: these are usually named $\boldsymbol{P}$. vulgaris and $\boldsymbol{P}$. mirabilis. Two of the most clear-cut differences between them are that the 'vulgaris' varieties rapidly ferment maltose and produce indole from tryptophan while 'mirabilis' is negative in both respects. The point under discussion centres round the fact that $\boldsymbol{P}$. vulgaris also ferments sucrose promptly, whereas $\boldsymbol{P}$. mirabilis strains ferment it late or not at all. It was shown (Coetzee \& Sacks, 1960a) that late sucrose fermentation by strains of $\boldsymbol{P}$. mirabilis was brought about by mutants capable of prompt fermentation, which arose in populations of the wild-type. Coetzee \& Hawtrey (1962) described a $P$. mirabilis strain which was cryptic (Cohen \& Monod, 1957) in regard to sucrose fermentation. This strain did not ferment sucrose and required more than 5 days in $1 \%(\mathrm{w} / \mathrm{v})$ sucrose peptone water to accumulate enough mutants to ferment the sugar. Sonic lysates of the wild 
strain did however contain an enzyme capable of cleaving sucrose to glucose + fructose. It was also found that lysing complexes of this strain + a virulent phage liberated an endolysin. This endolysin modified surface structures of uninfected organisms of the strain so that the latter were then able to ferment sucrose promptly. Permeability factors play a role in lactose fermentation by members of the family Enterobacteriaceae (Lowe, 1960; Li, Barksdale \& Garmise, 1961) and it was therefore decided to investigate sucrose fermentation by $\boldsymbol{P}$. hauseri from this point of view.

\section{METHODS}

Organisms. Ten Proteus vulgaris and $63 \boldsymbol{P}$. mirabilis strains were examined; they had been isolated from human stools and urine and were maintained on nutrient agar slopes at $4^{\circ}$. Also, a sucrose positive mutant $\left(s u c^{+}\right)$of $\boldsymbol{P}$. mirabilis strain 57 , isolated during the present work, was used in some experiments. The wild strains conformed to descriptions given by Kauffmann (1951); all were in the A phase (Coetzee \& Sacks, 1960b) and each gave a positive Dienes phenomenon (Krikler, 1953) with all other strains.

Media. All chemicals were A.R. grade and prepared media and other media constituents were Difco products. Saline was $\mathbf{0 . 8 5} \%(\mathrm{w} / \mathrm{v}) \mathrm{NaCl}$ in distilled water. Peptone water was made up of $1 \%(\mathrm{w} / \mathrm{v})$ peptone in saline with a phenol red indicator (Mackie \& McCartney; 1960). Sugars were added to the peptone water as Seitz filtrates to give $1 \%(\mathrm{w} / \mathrm{v})$ or $5 \%(\mathrm{w} / \mathrm{v})$ solutions. Nutrient agar consisted of nutrient broth with $1.5 \%(\mathrm{w} / \mathrm{v})$ agar. Sugar agar media consisted of nutrient agar containing neutral red $0.025 \mathrm{~g}$./1. and Seitz-filtered sugar solutions in distilled water to give concentrations of $1 \%(\mathrm{w} / \mathrm{v})$ or $5 \%(\mathrm{w} / \mathrm{v})$ at $46^{\circ}$. The sugar bile agar medium contained $1 \%(\mathrm{w} / \mathrm{v})$ sodium deoxycholate in addition. Before addition of sugars media were autoclaved at $120^{\circ}$ for $15 \mathrm{~min}$. All media were adjusted to $\mathrm{pH} \mathbf{7 \cdot 2}$.

Procedures. Liquid media were inoculated with one drop of an overnight broth culture delivered from a Pasteur pipette. When isolated colonies were required $\mathbf{0 . 1} \mathbf{~ m l}$. of suitable dilutions in distilled water of an overnight broth culture were spread to dryness with a sterile glass rod. Cultures were incubated aerobically at $37^{\circ}$. Mutation rates to sucrose fermentation were measured by enumerating papillae which arose on colonies on the $1 \%$ sucrose agar medium, according to methods previously used (Coetzee \& Sacks, 1960a).

Effect of sodium deoxycholate. Overnight broth cultures were diluted 1/4 in fresh broth and bubbled with sterile air for $2 \mathrm{hr}$. at $37^{\circ}$. Two ml. volumes were then centrifuged at $4000 \mathrm{rev} . / \mathrm{min}$. for $10 \mathrm{~min}$. and the deposited organisms (about $2 \times 10^{9}$ ) resuspended in $5 \mathrm{ml}$. of different concentrations of sodium deoxycholate in saline. On a few occasions duplicate sets of suspensions were made with the sodium deoxycholate dissolved in $\mathbf{0 . 6} \mathrm{M}$-sucrose in saline. This concentration of sucrose was known to keep penicillin-prepared protoplasts of Proteus hauseri intact (Coetzee; unpublished). After $30 \mathrm{~min}$. at room temperature the optical densities of the suspensions were read in a Zeiss spectrophotometer at $630 \mathrm{~m} \mu$.

Preparation of crude and partially purified cell extracts. Thirty-six hr. confluent growths of organism on nutrient agar or on $5 \%$ sucrose agar were harvested and washed 3 times with distilled water. The packed cell volumes were adjusted to haematocrit values of $35 \%$ and $25 \mathrm{ml}$. volumes of the suspensions disintegrated by 
vibrating in a Raytheon 50 W. 9 kc. sonic oscillator for $30 \mathrm{~min}$., the container being surrounded by a mixture of $\mathrm{NaCl}$ and ice. Unbroken organisms and large debris were deposited at $4000 \mathrm{rev} . / \mathrm{min}$. at $4^{\circ}$. The opalescent supernatant fluids ('crude extracts') were stored at $-10^{\circ}$. These crude extracts were partially purified by adding equal volumes of saturated ammonium sulphate and the precipitates deposited at $4000 \mathrm{rev} . / \mathrm{min}$. for $1 \mathrm{hr}$. in the cold. The precipitates were dissolved in $10 \mathrm{ml}$. distilled water and stored at $-10^{\circ}$. The protein content of these partially purified extracts was determined by a biuret method with ovalbumin as standard (Gornall, Bardwill \& David, 1949). On a few occasions 2 ml. benzene (Lowe, 1960) were added to the $25 \mathrm{ml}$. cell suspensions. The suspensions were agitated for $2 \mathrm{hr}$. at room temperature and then used as crude extracts. On other occasions 2 vol. of $2 \%(\mathrm{w} / \mathrm{v})$ sodium deoxycholate in saline were added to $25 \mathrm{ml}$. of cell suspensions to produce lysis of organisms; after shaking for $2 \mathrm{hr}$. at room temperature these were used as 'crude extracts'. Extracts were usually diluted 1/5 in distilled water before use.

Chromatography. Descending chromatography was done on Whatman no. 1 paper. The solvent system was ethyl acetate + acetic acid + formic acid + water in (18+ $3+1+4$, by vol.) The solvent was allowed to run for $16 \mathrm{hr}$. at room temperature and then $5 \%(\mathrm{w} / \mathrm{v}) p$-anisidine hydrochloride in $n$-butanol (Hough, Jones \& Wadman, 1950) used as the spray. Appropriate standard markers were used. When the presence of glucose-1-phosphate was investigated the chromatographic techniques of Colvin, Martin \& Dearing (1961) were used.

Enzyme assay procedure. Reaction tubes contained: $2.5 \mathrm{ml}$. 0.05 м-potassium phosphate buffer $(\mathrm{pH} 7 \cdot 4)+1 \cdot 0 \mathrm{ml} .0 \cdot 6 \mathrm{M}$-sucrose $+1 \cdot 0 \mathrm{ml}$. of a dilution of crude or partially purified extracts, + distilled water to $6 \mathrm{ml}$. Extract and substrate controls were included. The extract and other reactants were brought to $37^{\circ}$ in a water bath before mixing. Tubes were sampled at $5 \mathrm{~min}$. and $15 \mathrm{~min}$. Reducing sugars in these samples were measured by the method of Haslewood \& Strookman (1939) and the enzymic reaction stopped by pipetting the samples directly into the buffer + tungstate mixture of Haslewood \& Strookman used. Glucose in the samples was estimated by a glucose oxidase method for which the reagent was obtained from C. F. Boehringer and Son, Mannheim, Germany. With this method 0.1 ml. of sample was pipetted into $1 \mathrm{ml}$. of $0.05 \mathrm{M}$-potassium phosphate buffer $(\mathrm{pH} \mathrm{7.4})$ at $80^{\circ}$. The tubes were then placed in a beaker of boiling water for 2 min. This treatment did not hydrolyse sucrose and has been recommended by Bacon (1955) for stopping the enzyme reaction. After chilling, a $\mathbf{0 . 2} \mathrm{ml}$. sample from a tube was added to $5 \mathrm{ml}$. of oxidase reagent and the colour allowed to develop for $30 \mathrm{~min}$. in a $37^{\circ}$ water bath, the reaction then being stopped by adding $0.05 \mathrm{ml} .6 \mathrm{~N}-\mathrm{HCl}$. The colour was measured in a Zeiss spectrophotometer at $401 \mathrm{~m} \mu$. A glucose standard containing $91 \mu \mathrm{g}$. glucose $/ \mathrm{ml}$. was treated similarly. In experiments with partially purified extracts in a phosphate-free medium the potassium phosphate buffer used in the standard assay procedure was replaced by a sodium barbital buffer at $\mathrm{pH} 7 \cdot 4$, and the rate of breakdown of sucrose compared with a reaction proceeding simultaneously in phosphate buffer. The rate of the reaction was estimated by sampling the tubes at intervals and estimating reducing sugars. Phosphate in the barbital buffer reaction tubes was determined by the micro method of Berenblum \& Chain (1938).

Accumulation of disaccharides in Proteus hauseri. Confluent $36 \mathrm{hr}$. growths of 
organism on nutrient agar or on $1 \%$ or $5 \%$ sucrose agar were harvested and washed 3 times in distilled water. Very thick suspensions of between 114 and $127 \mathrm{mg}$. dry wt. organism $/ \mathrm{ml}$. were made in distilled water and $1 \mathrm{ml}$. added to $10 \mathrm{ml}$. of $1 \%$ sucrose peptone water in centrifuge tubes. One ml. lots of the very thick suspensions were also added to $10 \mathrm{ml}$. peptone water to serve as organism controls, while uninoculated sucrose peptone water served as the sucrose controls. Controls and tests were treated identically and experiments were done in triplicate. Tubes were kept at $37^{\circ}$ for $30 \mathrm{~min}$. and the organisms then deposited by centrifuging at $4000 \mathrm{rev} . / \mathrm{min}$. for $15 \mathrm{~min}$. at $4^{\circ}$. All the supernatant fluid was carefully removed from each tube and the sucrose in it estimated by treating $1 \mathrm{ml}$. as substrate in the enzyme assay procedure with $1 \mathrm{ml}$. of an invertase preparation derived from $P$. mirabilis strain U129. The amounts of glucose liberated in reaction periods of $30 \mathrm{~min}$. were then estimated by the glucose oxidase method. Results were expressed in mg. glucose/total specimen. The three supernatant fluids, each of the experiments done with strain $57 s u c^{+}$and $P$. vulgaris strains 9 and 15 were also investigated for the presence of extracellular $\beta$-D-fructofuranosidases. This was done by the enzyme assay procedure with sucrose as substrate and $1 \mathrm{ml}$. volumes of the supernatant fluids now treated as the enzyme preparations. Supernatant fluids were used as such and in more concentrated form by adding equal volumes of saturated ammonium sulphate, centrifugation at $4000 \mathrm{rev} . / \mathrm{min}$. for $1 \mathrm{hr}$. at $4^{\circ}$, and dissolving the precipitates in $2 \mathrm{ml}$. distilled water. The supernatant fluids of these three experiments were also chromatographed to detect the cleavage products (glucose, fructose) of possible extracellular enzymic activity. The deposits of organisms in the centrifuge tubes were carefully washed twice in cold distilled water and then suspended in $15 \mathrm{ml}$. of cold distilled water. Two of the three suspensions of each test were then disintegrated in the Raytheon oscillator, as described; the remaining test suspension and the control suspension were left intact. The amounts of sucrose present in the intact and disintegrated suspensions were estimated as above. Disintegrated and intact suspensions were also examined chromatographically for sucrose. Identical samples from the intact suspensions which had been exposed to sucrose and the control suspensions were dried and weighed to constant weight Mackie \& McCartney's Handbook, 1960). Experiments were also done on the uptake of maltose by different strains. These experiments differed from those described in that suspensions were made from $36 \mathrm{hr}$. growths on 1 and $5 \%$ maltose agar, $1 \%$ maltose peptone water was used and maltose in supernatant fluids and suspensions was determined by the copper reduction method.

\section{RESULTS}

\section{Sugar fermentations}

The results of sucrose fermentation tests are presented in Table 1. All 10 strains of Proteus vulgaris fermented $1 \%$ sucrose peptone water giving a small volume of gas within $24 \mathrm{hr}$. All members of $\boldsymbol{P}$. mirabilis groups $1 a, 1 b$ and 3 also fermented $1 \%$ sucrose peptone water giving a little gas; the time taken to do this was between 3 and 11 days. When the contents of these fermented tubes were plated on $1 \%$ sucrose agar, pale and many red colonies appeared after overnight incubation. The red colonies arose from mutants in the fermentation tubes capable of fermenting 
$1 \%$ sucrose peptone water within $24 \mathrm{hr}$. P. mirabilis strains of group 2 produced no indicator change in the sucrose peptone water even after incubation for 25 days. Strains of groups $1 a$ and $1 b$ fermented $5 \%$ sucrose peptone water giving a small volume of gas within $36 \mathrm{hr}$. When the contents of these fermented tubes were plated on $1 \%$ sucrose agar all colonies were pale. This proved that the rapid fermentation of $5 \%$ sucrose was not due to mutants capable of prompt sucrose fermentation. $P$. mirabilis strains of group 3 took more than 6 days to ferment $5 \%$ sucrose peptone water while strains belonging to group 2 produced no indicator change after 25 days of incubation. When the contents of the fermented tubes of group 3 were plated on $1 \%$ sucrose agar, pale and red colonies were observed. The red colonies originated from mutants capable of fermenting $1 \%$ sucrose peptone water within $24 \mathrm{hr}$.

Table 1. Sucrose fermentation by 73 strains of Proteus hauseri

Fluid media were inoculated with a drop of overnight broth culture. Solid media were inoculated with $0.1 \mathrm{ml}$. of a dilution of overnight broth culture in distilled water and rubbed to dryness with a sterile glass rod. Plates with about 10 colonies were examined. Cultures were incubated at $37^{\circ}$ and observed daily for 25 days.

\begin{tabular}{|c|c|c|c|c|c|}
\hline \multirow[b]{2}{*}{ Proteus } & \multirow[b]{2}{*}{ No. of strains } & \multirow{2}{*}{$\begin{array}{c}\text { Fermentation in } \\
1 \% \text { sucrose } \\
\text { peptone water }\end{array}$} & \multirow{2}{*}{$\begin{array}{c}\text { Fermentation in } \\
5 \% \text { sucrose } \\
\text { peptone water }\end{array}$} & \multicolumn{2}{|c|}{$\begin{array}{c}\text { Appearance } \\
\text { on } 1 \% \text { sucrose }\end{array}$} \\
\hline & & & & Agar & Bile agar \\
\hline 'vulgaris' & $\begin{array}{l}\text { 10, including } \\
\text { nos. } 9,15\end{array}$ & $\mathbf{A G}$ & $\mathbf{A G}$ & $\mathbf{R}$ & $\mathbf{R}$ \\
\hline $\begin{array}{l}\text { 'mirabilis' } \\
\text { Group } 1 a\end{array}$ & $\begin{array}{l}\text { 46, including } \\
\text { nos. F 25, U } 123 \text {, } \\
\text { U } 129, \text { U } 183\end{array}$ & $(\mathbf{A G})$ & AG* & $\mathbf{P}^{+}$ & $\mathbf{P}^{+}$ \\
\hline Group $1 b$ & $\begin{array}{l}\text { 9, including } \\
\text { nos. } 57, \text { F } 10\end{array}$ & (AG) & AG* & $\mathbf{P}^{+}$ & $\mathbf{R}^{+}$ \\
\hline Group 2 & $\begin{array}{l}\text { 8, nos. U18, F 20, } \\
40\end{array}$ & - & - & $\mathbf{P}$ & $\mathbf{P}$ \\
\hline Group 3 & $\begin{array}{l}5, \text { nos. } 12,13,34, \\
55,63\end{array}$ & $(\mathbf{A G})$ & (AG) & $\mathbf{P}^{+}$ & $\mathbf{P}^{+}$ \\
\hline
\end{tabular}

AG = acid with a small volume of gas within $24 \mathrm{hr} . ;(\mathrm{AG})=$ acid with a small volume of gas after more than 3 days; $P=$ pale overnight $; \mathbf{R}=$ red overnight. ${ }^{+}=$these colonies developed red papillae after more than 3 days; ${ }^{*}=$ acid with a small volume of gas within $36 \mathrm{hr}$.

Proteus did not swarm on the media used and isolated colonies of all the Proteus vulgaris strains were red after overnight incubation on $1 \%$ sucrose agar. $P$. mirabilis strains of groups $1 a$ and $1 b$ all formed pale colonies on the above medium; after about 3 days of incubation red papillae appeared on the colonies of all these 55 strains. Organisms from the papillae differed from the remainder of the colony in being able to ferment $1 \%$ sucrose peptone water within $24 \mathrm{hr}$. These papillae were the clonal progeny of mutations which occurred during the development of the colony and were selected by their ability to ferment sucrose (Coetzee \& Sacks, 1960 a). Strains of $\boldsymbol{P}$. mirabilis groups 2 and 3 also formed pale colonies on this sucrose agar medium, but whereas red papillae developed on the colonies of strains of group $\mathbf{3}$, papillae were never detected on colonies of group 2 even after 25 days of incubation.

A further phenotypic division was possible on the $1 \%$ sucrose bile agar medium. After overnight incubation well separated colonies of the $10 P$. vulgaris were red 
on this medium. Group 1 a P. mirabilis strains formed pale colonies which eventually developed sucrose fermenting papillae; group $1 b$ strains formed red colonies after overnight incubation. Organisms from these red colonies took more than 3 days to ferment $1 \%$ sucrose peptone water. Papillae also appeared after a few days on the red colonies of these 9 strains. They were small and less numerous than the papillae previously mentioned. Increasing the concentration of sodium deoxycholate up to $2 \%$ in the medium, did not change the appearance of group $1 a$ strains mentioned above. The appearance of strains of groups 2 and 3 on this medium was like that on $1 \%$ sucrose agar.

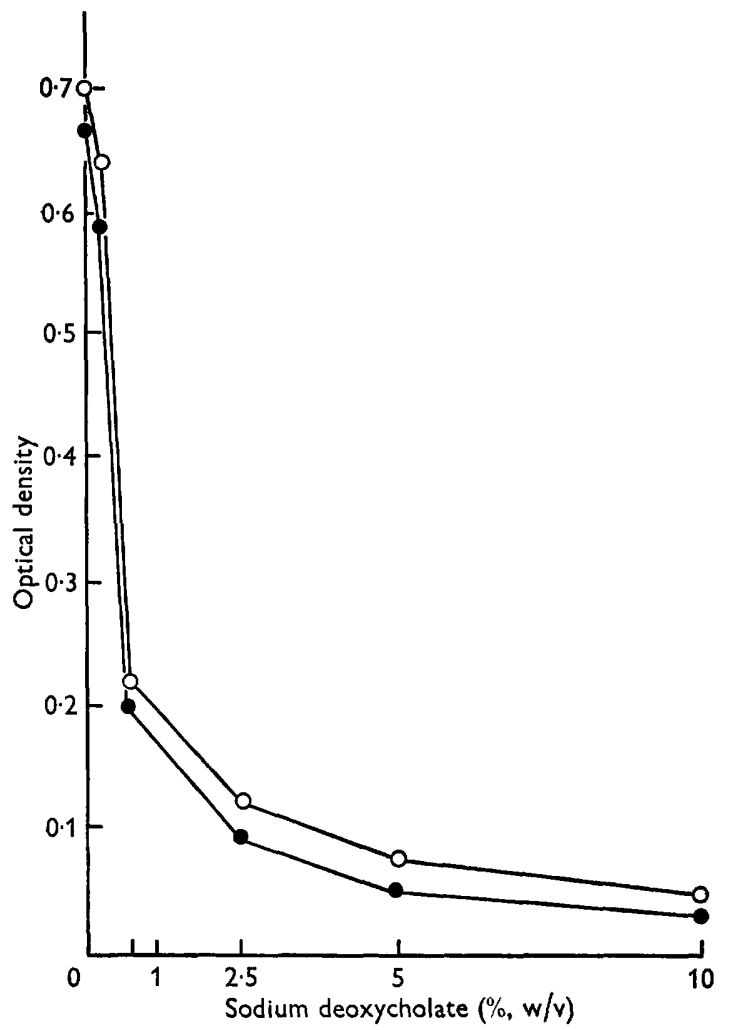

Fig. 1. Effect of sodium deoxycholate on Proteus mirabilis strain U 129. An overnight broth culture of Proteus mirabilis strain U129 was diluted 1/4 in fresh broth and bubbled with sterile air for $2 \mathrm{hr}$. at $37^{\circ} .2 \mathrm{ml}$. volumes were then sedimented at $4000 \mathrm{rev} . / \mathrm{min}$. for $10 \mathrm{~min}$. and the deposited organisms $\left(c .2 \times 10^{9}\right)$ resuspended in $5 \mathrm{ml}$. of various concentrations $(w / v)$ of sodium deoxycholate in saline $(\mathrm{O}-\mathrm{O})$. A duplicate set of suspensions was made with the sodium deoxycholate dissolved in $0.6 \mathrm{M}$ sucrose in saline $(0-0)$. Tubes were kept at room temperature for $30 \mathrm{~min}$. before reading densities with a Zeiss spectrophotometer at $630 \mathrm{~m} \mu$.

The mutation rates to sucrose fermentation of all strains of group 3, two strains of group $1 a$ (nos. U129, F 25) and one strain of group $1 b$ (no. 57) were investigated. These varied between $1 \times 10^{-9}$ bacteria/generation and $2 \times 10^{-9}$ bacteria/generation in different experiments with group 3 strains. The mutation rates for the strains of groups $1 a$ and $1 b$ ranged between $1 \times 10^{-8}$ and $5 \times 10^{8}$ bacteria/generation in different experiments. 
All ten Proteus vulgaris strains fermented $1 \%$ maltose peptone water within $24 \mathrm{hr}$. The $63 \boldsymbol{P}$. mirabilis strains did not ferment maltose, and none of the 73 Proteus strains fermented raffinose.

Effect of sodium deoxycholate on Proteus hauseri. Two 'vulgaris' strains, 10 members of group $1 a$ and all the members of groups $1 b, 2$ and 3 were used in these experiments. The results were identical in that all strains underwent visible clearing within $30 \mathrm{~min}$. in solutions of sodium deoxycholate down to concentrations of $0.6 \%(w / v)$. Viable counts done after $30 \mathrm{~min}$. from the $1 \cdot 2 \%(\mathrm{w} / \mathrm{v})$ sodium deoxycholate tubes indicated a $75 \%$ killing as compared with the saline control. Experiments conducted in $0.6 \mathrm{M}$-sucrose in saline showed no effect on the clearing of suspensions or viable counts. Periodic observations on the sucrose suspensions by phase-contrast microscopy showed normal forms with increasing amounts of debris. No protoplast-like structures were seen; this indicated that the mode of action of sodium deoxycholate was not only on the cell wall, but might affect the protoplasmic membrane, as suggested by Salton (1957) and by Pethica (1958) for the mode of action of other surface-active agents on Gram-negative bacteria. The result illustrated in Fig. 1 is representative of all strains tested.

\section{Examination of enzyme effects}

Crude enzyme extracts were prepared by the sonic treatment from two of the Proteus vulgaris strains $(9,15)$ and from all $63 P$. mirabilis strains grown on nutrient agar. These extracts were tested by the enzyme assay procedure for ability to cleave sucrose to fructose and glucose. Extract controls had very small reducing activity which never increased during the $10 \mathrm{~min}$. reaction period; chromatography of extracts and sucrose controls were satisfactory in that they never showed spots moving with glucose and fructose markers. Extracts from the $\boldsymbol{P}$. vulgaris strains and all members of groups $1 a$ and $1 b$ split sucrose to glucose + fructose as shown by chromatograms. The liberation of glucose and fructose from the non-reducing substrate was accompanied by a marked increase in the reducing activity of the $15 \mathrm{~min}$. sample over the 5 min. sample. No invert sugar was detected in any of the samples from tests with extracts of strains of groups 2 or 3 . New extracts of strains from groups 2 and 3 were prepared from organisms grown on $5 \%$ sucrose agar. Despite the fact that the period of sonic treatment produced marked clearing of the suspensions and that very few intact organisms were present as judged by microscopic observations, the results were negative. Crude extracts prepared from these 8 strains by the benzene and sodium deoxycholate methods were also inactive for sucrose, although control extracts produced from other 'mirabilis' strains by these methods yielded invert sugar.

Groups $1 a$ and $1 b$ comprising 55 of the 63 wild strains of Proteus mirabilis are thus cryptic with regard to sucrose fermentation, i.e. although they possess the relevant enzyme system, they do not normally ferment sucrose.

\section{Disaccharide accumulation studies}

Strains 57, F10, F25, U123, U129, U183 of groups $1 a$ and $1 b$, all members of groups 2 and 3, strain 57 suc $^{+}$and Proteus vulgaris strains 9, 15 were investigated to determine whether sucrose could accumulate in these organisms. With the exception of strains $57 s u c^{+}$and $P$. vulgaris strains 9 and 15, none of the strains examined 
normally metabolize sucrose. Representative results are shown in Table 2. Sucrose was identified chromatographically in the disintegrated suspensions of all members of group 3; none of the other suspensions (disintegrated or intact) showed the presence of sucrose. Despite the fact that recovery of sucrose (as glucose) with experiments on these group 3 strains was never more than about $85 \%$, it was deduced that sucrose from a $1 \%$ concentration in the medium, penetrated and was concentrated, by these 5 strains.

\title{
Table 2. Sucrose uptake by suspensions of Proteus mirabilis
}

\begin{abstract}
Thirty-six hr. growths on nutrient agar were washed 3 times in distilled water. Dense suspensions were made and $1 \mathrm{ml}$. added to $10 \mathrm{ml}$. of $1 \%$ sucrose peptone water. $1 \mathrm{ml}$. was also added to $10 \mathrm{ml}$. plain peptone water as organism control and uninoculated sucrose peptone water as sucrose control. Experiments were done in triplicate. Tubes were kept at $37^{\circ}$ for $30 \mathrm{~min}$., and then centrifuged at $4000 \mathrm{rev} . / \mathrm{min}$. for $15 \mathrm{~min}$. at $4^{\circ}$. Supernatant fluids were removed as completely as possible and deposits washed twice in cold distilled water. Deposits were then suspended in $15 \mathrm{ml}$. cold distilled water. Two of the three test suspensions of each experiment were disintegrated in a Raytheon sonic oscillator for $30 \mathrm{~min}$.; $1 \mathrm{ml}$. amounts of all tubes were then mixed with $1 \mathrm{ml}$. volumes of a partially purified extract of Proteus U 129 in the presence of $2.5 \mathrm{ml}$. 0.05 M-potassium phosphate buffer $\mathrm{pH} 7.4$ and $1.5 \mathrm{ml}$. distilled water. Extract and other reactants were equilibrated at $37^{\circ}$ before mixing. Tubes were sampled $30 \mathrm{~min}$. after mixing and the amount of glucose present determined by the glucose oxidase method.
\end{abstract}

Proteus mirabilis strains

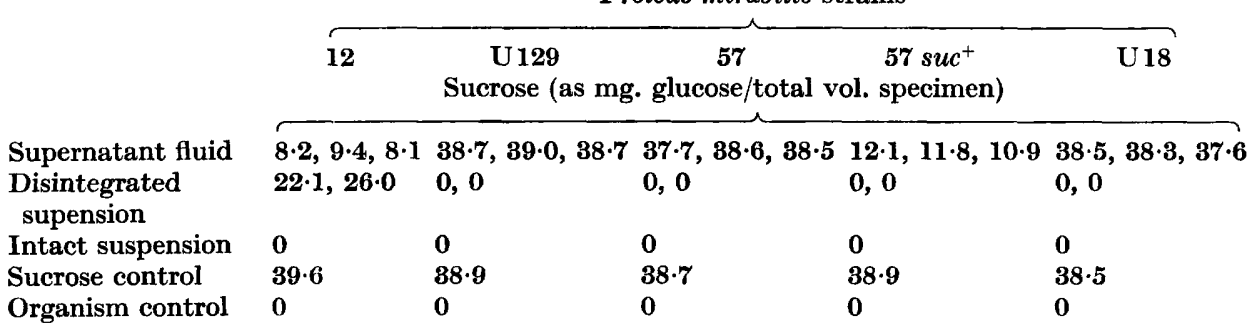

Strain $57 s u c^{+}$also removed large amounts of sucrose from sucrose + peptone water. Both the unconcentrated and concentrated supernatant fluids in experiments with strain $\mathbf{5 7}$ possessed no invertase activity as judged by the results of enzyme assays and by the fact that no spots corresponding to the glucose and fructose markers were seen on chromatograms from unconcentrated supernatant fluids. No sucrose, glucose or fructose was demonstrated chromatographically in the disintegrated or in the intact organism suspensions of strain $57 \mathrm{suc}^{+}$; no glucose was present in these suspensions as determined by the glucose oxidase method. Experiments with Proteus vulgaris (strains 9, 15) yielded similar results to those with strain $57 s u c^{+}$. The results with the above three strains may be taken to mean that their sucrose splitting enzymes are intracellular. It appears that the sucrose which disappeared from sucrose peptone water penetrated these organisms in the disaccharide form and once in contact with the enzyme inside the cells was rapidly split and further metabolized (Cohen \& Monod, 1957). Sucrose did not enter organisms of groups $1 a, 1 b$ or 2 .

The experiments with these 9 strains of groups $1 a, 1 b$ and 2 were repeated with organisms harvested from $36 \mathrm{hr} .1 \%$ and $5 \%$ sucrose agar plates, with similar results. Four separate experiments were done on dry weights of identical samples 
from the suspensions of all members of group 3 and corresponding control suspensions which had been exposed to sucrose. In all four experiments the test suspensions were $11 \cdot 0-14 \cdot 8 \%$ heavier than the controls. In similar experiments with the members of group 2 test suspensions were either heavier or lighter than the controls; the differences did not exceed $2 \%$ of the control weight. Although strains belonging to groups 2 and 3 all lacked sucrose splitting enzymes group 2 strains could thus be distinguished on a basis of sucrose uptake.

Table 3. Maltose uptake by suspensions of Proteus hauseri

Thirty-six hr. growths on $5 \%$ maltose agar were washed 3 times in distilled water. Dense suspensions were made and $1 \mathrm{ml}$. added to $10 \mathrm{ml}$. of $1 \%$ maltose peptone water. $1 \mathrm{ml}$. was also added to $10 \mathrm{ml}$. plain peptone water as organism control, and uninoculated maltose peptone water served as maltose control. Experiments were done in triplicate. Tubes were kept at $37^{\circ}$ for $30 \mathrm{~min}$. and then centrifuged at $4000 \mathrm{rev} . / \mathrm{min}$. for $15 \mathrm{~min}$. at $4^{\circ}$. Superanatant fluids were removed as completely as possible and the deposits carefully washed twice in cold distilled water. Deposits were suspended in $15 \mathrm{ml}$. cold distilled water and two of the three test suspensions of each experiment disintegrated in a Raytheon sonic oscillator for $30 \mathrm{~min}$. Reducing activity in all tubes was then determined.

Proteus mirabilis strains

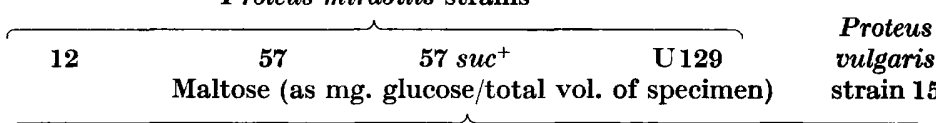

Supernatant fluid $49 \cdot 5,49 \cdot 6,49 \cdot 750 \cdot 2,49 \cdot 7,49 \cdot 748 \cdot 9,49 \cdot 7,47 \cdot 949 \cdot 5,49 \cdot 0,48 \cdot 910 \cdot 1,9 \cdot 5,816$

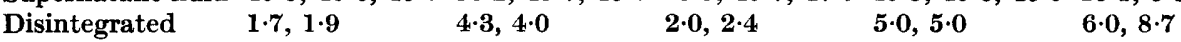

suspension

Intact suspension 1.8

Maltose control $\quad \mathbf{4 9 \cdot 5}$

$4 \cdot 4$

$49 \cdot 7$

$4 \cdot 3$

$\begin{array}{rrr}2 \cdot 1 & 4 \cdot 8 & 2 \cdot 8 \\ 49 \cdot 5 & 49 \cdot 0 & 49 \cdot 1 \\ 2 \cdot 4 & 4 \cdot 8 & 2 \cdot 1\end{array}$

Table 3 illustrates the results obtained in an experiment on maltose uptake by Proteus mirabilis strains 12, 57,57 suc $^{+}$and U129 and $P$. vulgaris strain 15, all grown on $5 \%$ maltose agar.

None of the Proteus mirabilis strains removed maltose from maltose peptone water and maltose was not found chromatographically in disintegrated suspensions of the strains exposed to maltose. The other $P$. mirabilis strains of groups 2 and 3 tested, yielded similar results. These experiments were repeated with suspensions prepared from organisms grown on $1 \%$ maltose agar and gave similar results. $P$. vulgaris strain 15 removed about $80 \%$ of the maltose from the peptone water; no maltose or glucose was found chromatographically in the disintegrated or intact suspensions of this strain. This and the fact that less than one-third of the input of reducing activity was recovered may be attributed to rapid further metabolism of disaccharide once it was taken up by Proteus 15. A measure of selective permeability for disaccharides was thus exhibited by strains of group 3 and $\boldsymbol{P}$. mirabilis strain $\mathbf{5 7}$ $s u c^{+}$. While impermeable to maltose these organisms took up sucrose from the medium despite the fact that group 3 strains had no means of metabolizing it.

\section{Properties of partially purified enzymes}

Extracts of Proteus vulgaris strains 15 and 9 and $P$. mirabilis strains 57 and U129 were studied in greater detail. The evidence against a phosphorolytic mechanism of sucrose breakdown in the organisms studied here is that in experiments with partially 
purified enzyme extracts the breakdown of sucrose proceeded at the same rate in both barbital and phosphate buffers. The amount of phosphate in the barbital reaction mixture was less than $10^{-6} \mathrm{M}$. No spot corresponding to the glucose-1phosphate marker was seen on special chromatograms. These findings taken in conjunction with the fact that glucose was detected in the reaction mixtures by the glucose oxidase enzyme (which does not react with glucose-1-phosphate) and that

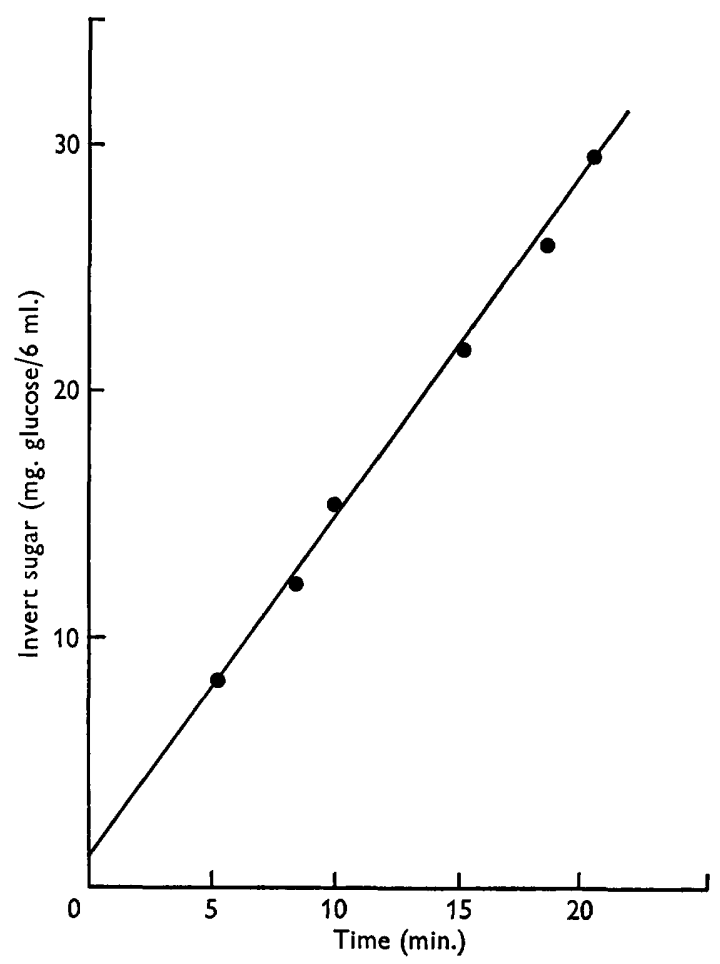

Fig. 2. Relationship between time and quantity of invert sugar produced from sucrose by a partially purified extract of Proteus mirabilis strain 5\%. The reaction mixture contained $1 \mathrm{ml} .0 .6 \mathrm{M}$-sucrose, $1 \mathrm{ml}$. of a $1 / 5$ dilution of a partially purified extract of $P$. mirabilis strain 57 in distilled water, $2.5 \mathrm{ml}$. of $0.05 \mathrm{M}$-potassium phosphate buffer $\mathrm{pH} 7 \cdot 4$ and $1.5 \mathrm{ml}$. distilled water. The extract and other reactants were equilibrated at $37^{\circ}$ before mixing. Samples were removed at intervals and reducing activity measured. This was expressed as mg. glucose $/ 6 \mathrm{ml}$.

glucose and fructose were identified chromatographically in these mixtures, excludes the presence of sucrose phosphorylase, levansucrase and dextransucrase (Hassid, 1951). This labels the responsible enzyme in all four partially purified extracts as an invertase.

Linear relationships were found between the quantities of invert sugar produced and the time periods of reaction and the amounts of extract in reaction mixtures. Figures 2 and 3 illustrate these findings for the partially purified extract of Proteus mirabilis strain $\mathbf{5 7 .}$

The $\mathrm{pH}$ optima for invertase activity of all four partially purified extracts was about $\mathrm{pH} 7 \cdot 4$. Figure 4 shows the results obtained with the extract from proteus 
strain 15. The invertase from Aspergillus oryzae has an optimum between 6 and 8 , but most invertases have $\mathrm{pH}$ optima ranging from $4 \cdot 2$ to $7 \cdot 0$ (Neuberg \& Mandl, 1951), and the invertase of Saccharomyces cerevisiae has an optimum of $\mathrm{pH} \mathbf{4} \cdot \mathbf{7 - 4} \cdot \mathbf{9}$ (Bacon, 1955).

The effect of different salts on the invertase activity of partially purified extracts was tested; the results of one experiment with a partially purified extract of Proteus mirabilis strain $\mathbf{5 7}$ is presented in Table 4.

It is seen that $\mathrm{K}^{+}$and $\mathrm{NH}_{4}+$ had a stimulatory action while $\mathrm{Na}^{+}, \mathrm{Li}^{+}, \mathrm{Mg}^{+}$and

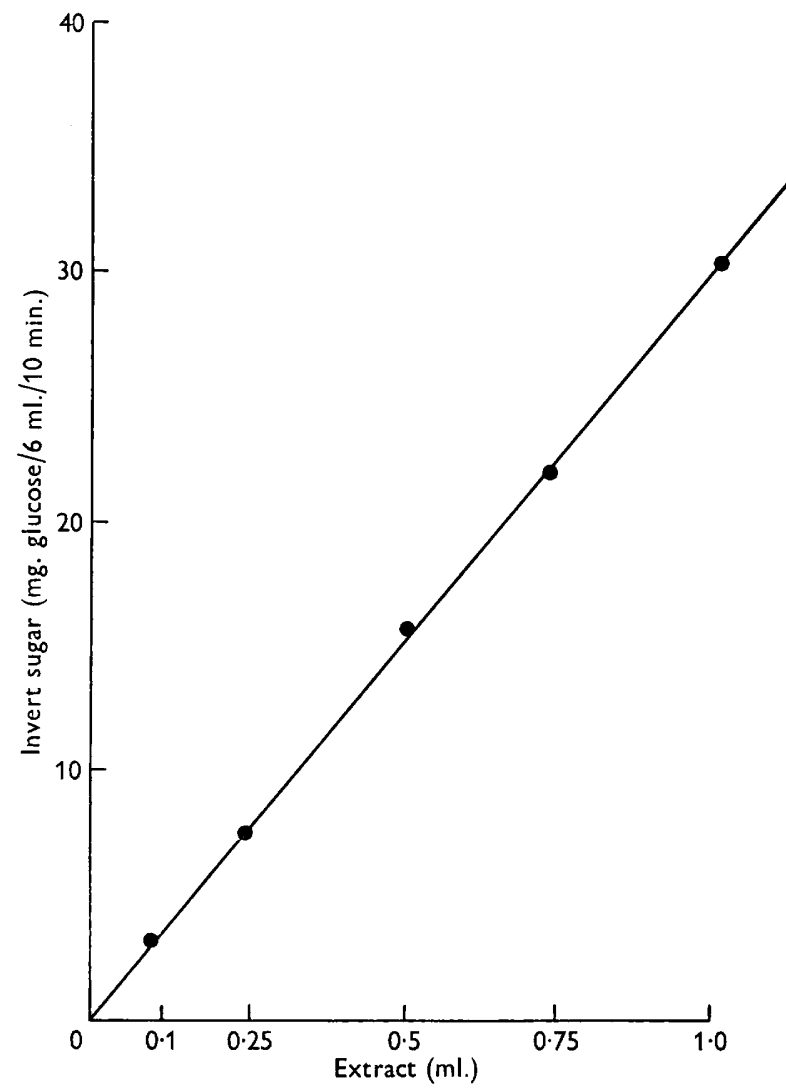

Fig. 3. Relationship between amount of invert sugar produced from sucrose by different quantities of a partially purified extract of Proteus mirabilis strain 57. Reaction mixtures contained $1 \mathrm{ml}$. of $0.6 \mathrm{M}$ sucrose, different volumes of a $1 / 5$ dilution of a partially purified extract of Proteus mirabilis strain 57 in distilled water to $1 \mathrm{ml}$., $2.5 \mathrm{ml}$. of $0.05 \mathrm{M}$-potassium phosphate buffer $\mathrm{pH} 7 \cdot 4$ and distilled water to $6 \mathrm{ml}$. Extracts and other reactants were equilibrated at $37^{\circ}$ before mixing. Samples were removed after $5 \mathrm{~min}$. and $15 \mathrm{~min}$. and reducing activity measured. This was expressed as $\mathrm{mg}$. glucose $/ 6 \mathrm{ml}$. and the amount produced in the $10 \mathrm{~min}$. interval calculated.

$\mathrm{Ca}^{2+}$ were inert; the anions phosphate, chloride, citrate and sulphate also had no effect. The enzymic activity was not influenced by sodium deoxycholate; like other invertases (Neuberg \& Mandl, 1951) it was not affected by sodium fluoride. The activities of the other partially purified extracts were like those of strain 57 in the different ionic environments. All four partially purified extracts split raffinose to 
melibiose + fructose. These products were identified chromatographically in reaction mixtures containing raffinose as substrate. No glucose was found. This was proved chromatographically and also by testing samples from the reaction tubes by the glucose oxidase method which does not react with either fructose or melibiose.

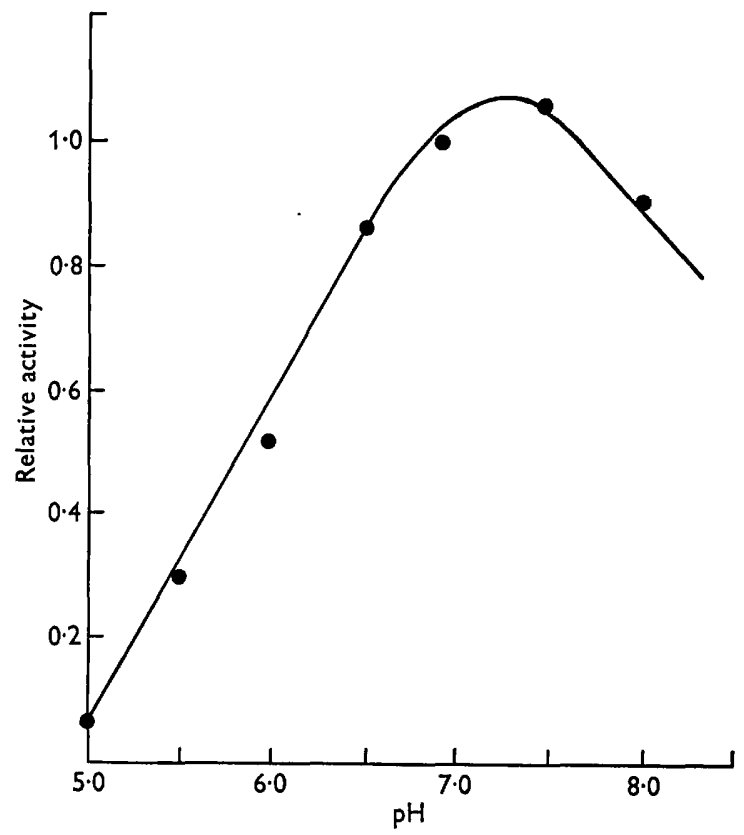

Fig. 4. Effect of $\mathrm{pH}$ on invertase activity of a partially purified extract of Proteus vulgaris strain 15. Reaction tubes contained $1 \mathrm{ml}$. of a partially purified extract of $P$. vulgaris strain 15 diluted $1 / 5$ in distilled water, $1 \mathrm{ml}$. of $0.6 \mathrm{M}$-sucrose and $3.5 \mathrm{mI} .0 .05 \mathrm{M}$ potassium phosphate buffer at different $\mathrm{pH}$ values. Extracts and other reactants were equilibrated at $37^{\circ}$ before mixing. Samples were withdrawn after $5 \mathrm{~min}$. and $15 \mathrm{~min}$. and reducing activity measured. These were expressed as $\mathrm{mg}$. glucose/6 $\mathrm{ml}$. and the amount produced in the $10 \mathrm{~min}$. interval calculated. The activity units were arbitrary and were adjusted for unit activity at $\mathrm{pH} 7$.

\section{Table 4. Influence of salts on invertase activity of extracts of Proteus mirabilis 57}

Reaction tubes contained: $1 \mathrm{ml}$. $1 / 5$ dilution of a partially purified extract of proteus 57; $1 \mathrm{ml}$. 0.6 M-sucrose; $2.5 \mathrm{ml}$. 0.05 M-tris buffer (pH 7.4) : $1.5 \mathrm{ml}$. $0 \cdot 16 \mathrm{M}$ solution of different salts. The control tube had the $1.5 \mathrm{ml}$. salt solution replaced by distilled water. Extracts and other reactants were temperature equilibrated at $37^{\circ}$ before mixing. Tubes were sampled after 5 and 15 min. and reducing activity (as glucose) measured.

\section{Salt}

Potassium chloride

Potassium dihydrogen phosphate

Ammonium citrate

Ammonium chloride

Magnesium chloride

Lithium sulphate
Reaction rate (mg. glucose/ $6 \mathrm{ml} . / 10 \mathrm{~min}$.)
Reaction rate (mg. glucose/ Salt $6 \mathrm{ml} . / 10 \mathrm{~min}$.)

Calcium chloride

Sodium phosphate

$4 \cdot 1$

Sodium chloride

$4 \cdot 8$

$5 \cdot 0$

$4 \cdot 4$

Sodium fluoride $\quad \mathbf{4} \cdot \mathbf{9}$

Sodium deoxycholate $\quad \mathbf{4 . 5}$

Distilled water control $\quad \mathbf{4} \cdot \mathbf{4}$ 
A plot of raffinose concentration and reaction rate is presented in Fig. 5 for a partially purified extract prepared from Proteus U129. Michaelis constants calculated from the slopes and ordinate intercepts according to Lineweaver \& Burk (1934) yielded values of $0.114 \mathrm{M}, 0.210 \mathrm{M}, 0.125 \mathrm{M}$ and $0.245 \mathrm{M}$ for the extracts of Proteus strains $\mathrm{U} 129,5 \%, 15$ and 9 , respectively.

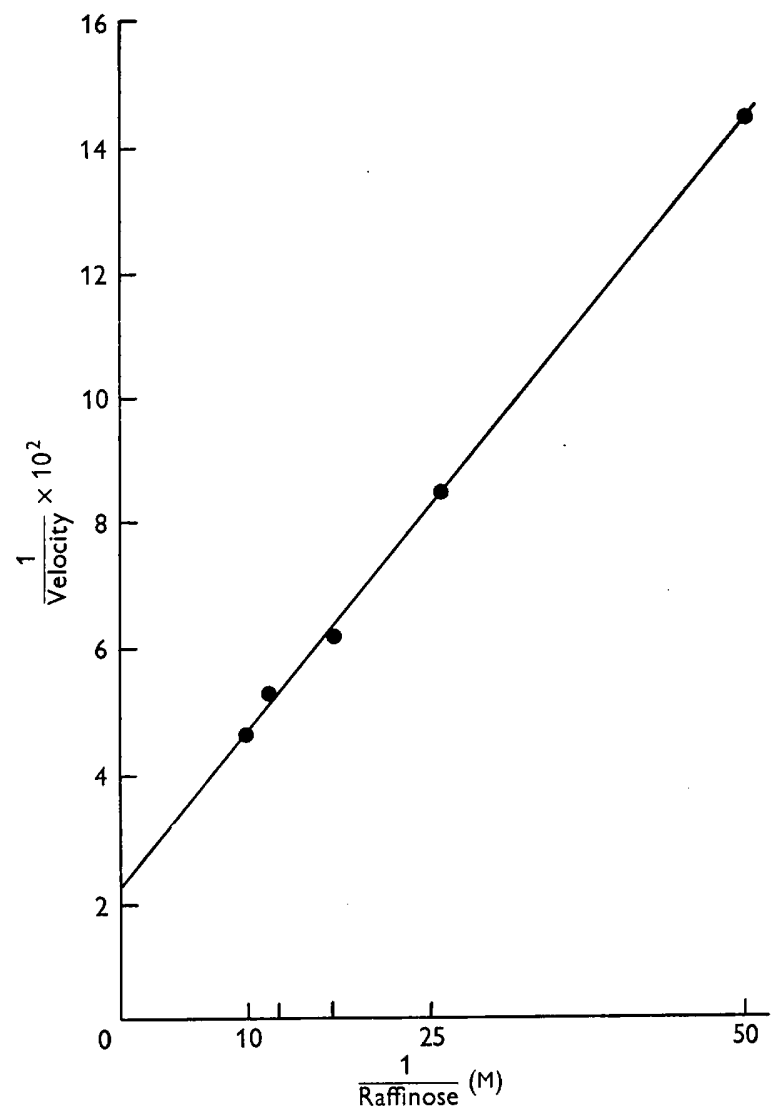

Fig. 5. Breakdown of raffinose by a partially purified extract of Proteus mirabilis strain U129. Reaction tubes contained $1 \mathrm{ml}$. of a partially purified extract of U129 diluted $1 / 5$ in distilled water, different volumes of $0.6 \mathrm{M}$-raffinose, $2.5 \mathrm{ml}$. of $0.05 \mathrm{M}$-potassium phosphate buffer pH 7.4 and distilled water to $6 \mathrm{ml}$. Extracts and other reactants were equilibrated at $37^{\circ}$ before mixing. Samples were removed after $5 \mathrm{~min}$. and $15 \mathrm{~min}$. and reducing activity (expressed as glucose) determined. Reaction velocities were expressed as $\mathrm{mg}$. glucose $/ 6 \mathrm{ml} . / 10 \mathrm{~min}$.

Although only strains 57 and U129 have been investigated it is probable that all 55 strains of groups $1 a$ and $1 b$ cryptic with regard to sucrose fermentation are thus also cryptic towards raffinose.

The kinetic behaviour of mixtures of raffinose and sucrose in the presence of a partially purified extract of Proteus U129 is presented in Fig. 6. The ordinate intercept of the straight lines indicate that raffinose was a competitive inhibitor of sucrose for the enzyme which may now be termed a $\beta$-D-fructofuranosidase. Similar results were obtained with partially purified extracts from the other three strains; 
Michaelis constants for the enzyme present in the extracts from strains U129, 57, 15 and 9 with sucrose as substrate are $0.026,0.031,0.018$ and $0.028 \mathrm{M}$, respectively. The constants are of the same order as the values reported for yeast and gut saccharases (Baldwin, 1947).

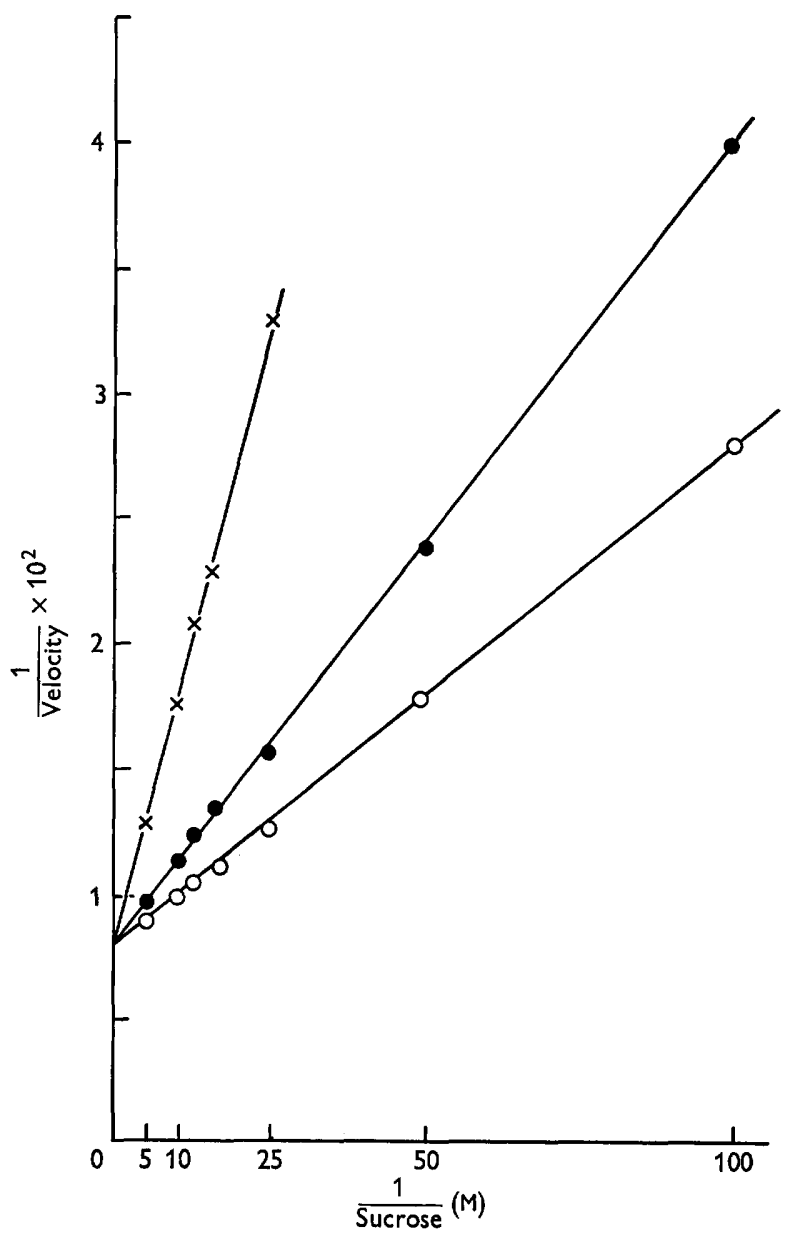

Fig. 6. Competitive inhibition of sucrose by raffinose in the presence of a partially purified extract of Proteus U 129. Reaction tubes contained $1 \mathrm{ml}$. of a partially purified extract of Proteus U129 diluted $1 / 5$ in distilled water, $2.5 \mathrm{ml}$. of $0.05 \mathrm{M}$-potassium buffer $\mathrm{pH} 7 \cdot 4$ and different volumes of $0 \cdot 6 \mathrm{M}$-sucrose. Tubes of experiment $(\mathrm{O}-\mathrm{O})$ also contained $0 \cdot 1 \mathrm{ml}$. of $0.6 \mathrm{M}$-raffinose and those of experiment $(x-\times)$ contained $1 \mathrm{ml}$. of $1 \mathrm{M}$-raffinose. Contents of tubes were made up to $6 \mathrm{ml}$. with distilled water. The extracts and other reactants were equilibrated at $37^{\circ}$ before mixing. Samples were removed after 5 min. and 15 min. and the glucose content determined by the glucose oxidase method. Reaction velocities were expressed as $\mathrm{mg}$. glucose $/ 6 \mathrm{ml} . / 10 \mathrm{~min}$.

Table 5 gives the results of reaction rate experiments with partially purified extracts of Proteus mirabilis strains U129, 57 and $P$. vulgaris strains 15, 9 from $24 \mathrm{hr}$. growth on nutrient agar and $1 \%$ glucose and sucrose agar, respectively. The same amounts of extract proteins were added to the tubes and the results were comparable. The reaction velocities found were very similar for extracts prepared 
from any one of these four strains grown on either nutrient agar, $1 \%$ glucose or sucrose agar and implied that the $\beta$-D-fructofuranosidase was constitutive in the strains tested.

\title{
Table 5. Reaction rate experiments with partially purified extracts of Proteus grown on different media
}

\begin{abstract}
Partially purified extracts were prepared from $36 \mathrm{hr}$. growths of organism on nutrient agar, $1 \%(w / v)$ glucose agar and $1 \%(w / v)$ sucrose agar. The protein content of extracts was adjusted to $4 \mathrm{mg}$. $/ \mathrm{ml}$. Reaction tubes contained: $1 \mathrm{ml}$. extract $+1 \mathrm{ml} .0 \cdot 6 \mathrm{M}$-sucrose $+2.5 \mathrm{ml}$. 0.05 M-potassium phosphate buffer $(\mathrm{pH} 7 \cdot 4)+1.5 \mathrm{ml}$. distilled water. Extracts and other reactants were equilibrated at $37^{\circ}$ before mixing. Tubes were sampled after $5 \mathrm{~min}$. and $15 \mathrm{~min}$. and glucose estimated by the glucose oxidase method.
\end{abstract}

\begin{tabular}{|c|c|c|c|}
\hline \multirow{3}{*}{$\begin{array}{c}\text { Extract from } \\
\text { Proteus } \\
\text { strain }\end{array}$} & \multicolumn{3}{|c|}{ Extracts prepared from organisms grown on } \\
\hline & Nutrient agar & $\begin{array}{c}1 \%(w / v) \\
\text { Glucose agar }\end{array}$ & $\begin{array}{c}1 \%(w / v) \\
\text { Sucrose agar }\end{array}$ \\
\hline & \multicolumn{3}{|c|}{ Reaction rates (mg. glucose $/ 6 \mathrm{ml} . / 10 \mathrm{~min}$. ) } \\
\hline U 129 & $\mathbf{2 \cdot 0}$ & $\mathbf{2 \cdot 4}$ & $\mathbf{2 \cdot 0}$ \\
\hline 57 & $2 \cdot 7$ & $\mathbf{2 \cdot 3}$ & $\mathbf{2 \cdot 3}$ \\
\hline 15 & $3 \cdot 1$ & $\mathbf{3 \cdot 2}$ & $\mathbf{2 \cdot 9}$ \\
\hline 9 & $1 \cdot 7$ & $\mathbf{2 \cdot 0}$ & $\mathbf{2 \cdot 0}$ \\
\hline
\end{tabular}

\section{DISCUSSION}

Cohen \& Monod (1957) proposed two models to account for the fact that organisms like those of Proteus mirabilis group 3 can accumulate large amounts of a substrate. The stoichiometric model explains this unidirectional transfer as a result of the binding of substrate to intracellular macromolecular receptors. No permeable barrier or special permeation mechanism is implicated. The catalytic theory explains the accumulation on the basis of a virtually impermeable osmotic barrier which the substrate (sucrose) can cross only by combining with a specific enzyme, called a permease. The fact that the strains of Proteus mentioned accumulated sucrose up to about $14 \%$ of their dry weight is strongly against the first model. This would demand an impossibly large number of non-diffusable macromolecular (presumably protein) absorption sites. On the other hand, it was found that 55 of 63 wild strains of $\boldsymbol{P}$. mirabilis were impermeable to $1 \%$ solutions of sucrose while they did possess $\beta$-D-fructofuranosidases (cryptic strains). Strains of group 3 were selectively permeable to $1 \%$ sucrose but had no invertase; members of group 2 were impermeable and also lacked $\beta$-D-fructofuranosidases. The $\beta$-D-fructofuranosidases appeared to be confined within the cells. No extracellular invertase activity was detected with suspensions of a sucrose-positive mutant of a cryptic strain and of two $\boldsymbol{P}$. vulgaris strains investigated. The existence of the above phenotypes shows that selective permeability to sucrose and $\beta$-D-fructofuranosidase activity are two genetically and functionally distinct properties and that they normally form a metabolic sequence in vivo; these observations are strongly in favour of the permease model. In this respect it may be noted that strains of group 3 had lower mutation rates to sucrose utilization than three representatives (strains U129, F25 and 57) of the cryptic group. This is supporting evidence for the contention that factors which control 
the $\beta$-D-fructofuranosidase and selective permeability to sucrose are genetically distinct. The methods at our disposal for the sucrose uptake studies were crude and devious. For these reasons no kinetic studies on sucrose accumulation were attempted and no sucrose permease was demonstrated. The system which controls the selective permeation of sucrose in $\boldsymbol{P}$. hauseri will consequently be named a sucrose permeability factor.

A number of workers (Kriebel, 1934; Chilton \& Fulton, 1946; Lowe \& Evans, 1957 ; Lowe, 1960) have observed that when the concentration of lactose is increased above the usual $1 \%$ many paracolon organisms ferment this disaccharide in a shorter time. Lowe (1960) showed that many paracolon strains were cryptic in respect to lactose but when the concentrations were increased to $5 \%$ the permeability of the barrier which separates the $\beta$-galactosidase from its substrate was increased, permitting the entry of some lactose. Cohen \& Monod (1957) assumed that the barrier of the cell was not absolutely impermeable and they invoked 'nonspecific leakage' to equilibrate the entry of substrate by the specific permease system. A similar phenomenon was encountered in this work where all 55 cryptic strains of Proteus mirabilis were found to ferment $5 \%$ sucrose peptone water within $36 \mathrm{hr}$., while requiring 3-11 days to ferment $1 \%$ sucrose. Fermentation at the latter concentration was due to the selection of mutants like those of $\boldsymbol{P}$. mirabilis strain $57 \mathrm{suc}^{+}$which were permeable to $1 \%$ sucrose and thus capable of prompt sucrose fermentation. No organisms capable of fermenting $1 \%$ sucrose promptly were isolated from the $5 \%$ tubes when these were examined at $36 \mathrm{hr}$. It may be postulated that the barrier which separates the $\beta$-D-fructofuranosidase from external sucrose in the cryptic strains is not wholly impermeable to high concentrations of the latter.

It was demonstrated that all Proteus strains tested underwent marked lysis in the presence of $1 \%$ sodium deoxycholate. It was also shown that the action of the bile was not confined to the cell wall. To account for the fact that cryptic strains promptly ferment $1 \%$ sucrose in the sucrose bile agar medium it is only necessary to assume that the barrier, which is possibly the protoplast-limiting membrane (Cohen \& Monod, 1957), is made more permeable to sucrose by the action of sodium deoxycholate. The problem is why only 9 out of the 55 cryptic strains showed this phenomenon. No difference in bile sensitivity was demonstrated and increasing the concentration of sodium deoxycholate in the sucrose agar had no effect. It was also shown that the $\beta$-D-fructofuranosidase of these strains was not affected by similar concentrations of sodium deoxycholate and it must be concluded that subtle differences exist between strains of the cryptic group which were not detected.

From the results obtained a classification of the strains of Proteus hauseri investigated is presented in Table 6. Rustigan \& Stuart (1945) reported that 197 of 205 strains of $\boldsymbol{P}$. mirabilis fermented sucrose slowly, while the remaining 8 strains failed to ferment it after 21 days of incubation. The fermentation of sucrose by Kauffmann's (1951) 456 P. mirabilis strains was also 'late, irregular or negative'. From the information available it is thus impossible to decide to which of the proposed phenotypes the slow sucrose-fermenting organisms in the series of Rustigan \& Stuart or Kauffmann belong. The 8 strains of the former authors and the unspecified number of Kauffmann which do not ferment sucrose even after long periods of incubation, are almost certainly however of the phenotype which lacks both $\beta$-D-fructofuranosidase and the permeability factor. 


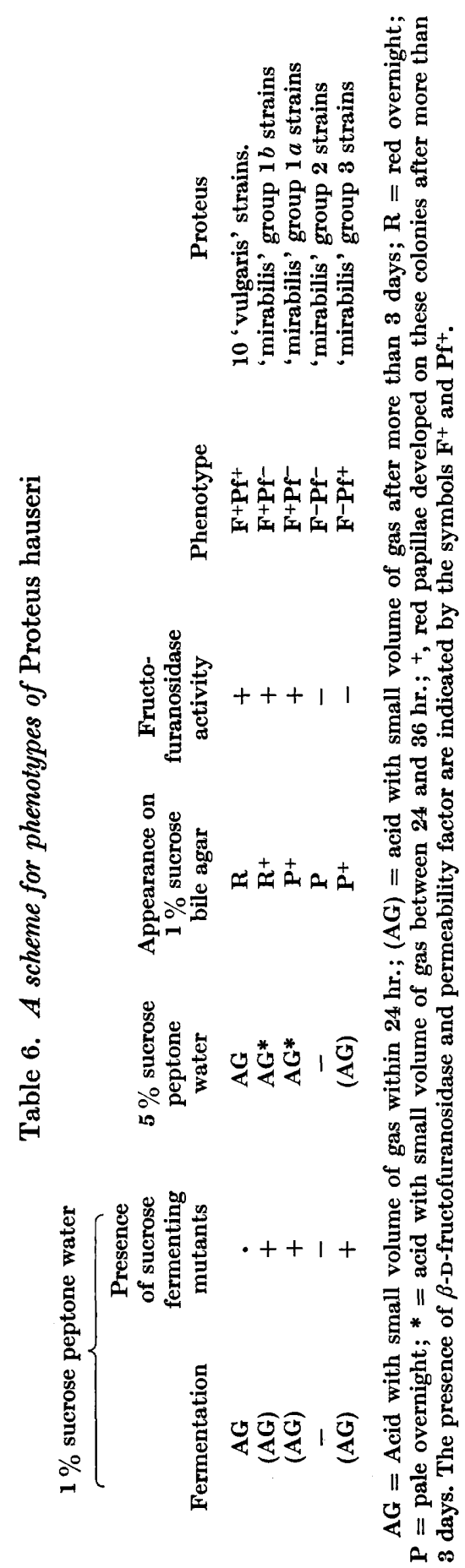


Acknowledgement is made to Miss C. J. Bosman and Miss G. Pernet for technical assistance rendered. The author was in receipt of a grant from the South African Council for Scientific and Industrial Research.

\section{REFERENCES}

BAcon, J. S. D. (1955). Methods for measuring transglycosylase activity of invertases. Methods in Enzymology, 1, 258. Ed. by S. P. Colowick \& N. O. Kaplan, New York: Academic Press.

Baldwin, E. (1947). Dynamic Aspects of Biochemistry, Cambridge University Press.

Berenblum, I. \& Chain, E. (1938). An improved method for the colorimetric determination of phosphate. Biochem. J. 32, 295.

Chilton, M. L. \& Fulton, McD. (1946). A presumptive medium for differentiating paracolon from Salmonella cultures. J. Lab. clin. Med. 31, 824.

Coetzee, J. N. \& Hawtrey, A. O. (1962). A change in phenotype associated with the bacteriophage carrier state in a strain of Proteus mirabilis. Nature, Lond. 194, 1196.

Coetzee, J. N. \& SAcks, T. G. (1960a). The late sucrose fermenting property of Proteus mirabilis. S. Afr. J. Lab. clin. Med. 6, 49.

Coktzee, J. N. \& SACks, T. G. (1960b). Morphological variants of Proteus hauseri. J. gen. Microbiol. 23, 209.

Cohen, G. N. \& Monod, J. (1957). Bacterial permeases. Bact. Rev. 21, 169.

Colvin, J. R., Martin, S. M. \& Dearing, G. G. (1961). Extracellular glucose. 1. Phosphate in Acetobacter xylinum and its role in cellulose synthesis. Canad. J. Biochem. 39, 493.

Gornall, A. G., Bardwill, C. J. \& David, M. M. (1949). Determination of serum proteins by means of the Biuret reaction. J. biol. Chem. 177, 751.

Haslewood, G. A. D. \& Strookman, T. A. (1939). A method for the estimation of 'true' sugar in $0.05 \mathrm{ml}$. of blood. Biochem. J. 33, 920 .

Hassid, W. Z. (1951). Metabolism of Polysaccharides and Disacharides. Phosphorus Metabolism, p. 11. Ed. by W. D. McElroy \& B. Glass. Baltimore: Johns Hopkins Press.

Hough, L., Jones, J. K. N. \& Wadman, W. H. (1950). Quantitative analysis of mixtures of sugars by the method of partition chromatography. Part V. Improved methods for the separation and detection of the sugars and their methylated derivatives on the paper chromatogram. J. chem. Soc. ii, 1702.

Kauffmann, F. (1951). Enterobacteriaceae. Copenhagen: Munksgaard.

KRIEBEL, R. M. (1934). A comparative bacteriological study of a group of non-lactosefermenting bacteria isolated from stools of healthy foodhandlers. J. Bact. 27, 357 .

Krikler, M. S. (1953). The Serology of Proteus vulgaris. Ph.D. Thesis: University of London.

Li, K., Barksuale, L. \& Garmise, L. (1961). Phenotypic alterations associated with the bacteriophage carrier state of Shigella dysenteriae. J. gen. Microbiol. 24, 355.

Lineweaver, H. \& Burk, D. (1934). The determination of enzyme dissociation constants. J. Amer. chem. Soc. 56, 658.

Lowe, G. H. \& Evans, J. H. (1957). A simple medium for the rapid detection of salmonellalike paracolon organisms. J. clin. Path. 10, 318.

Lowe, G. H. (1960). A study of the factors controlling lactose-fermentation in the coliform and paracolon groups. J. gen. Microbiol. 23, 127.

Mackie \& McCartney's Handbook of Bacteriology (1960). Ed. by R. Cruickshank, 10th ed. Edinburgh: E. and S. Livingstone Ltd.

Neuberg, C. \& Mandu, I. (1951). Invertase. The Enzymes, 1, pt. 1, 527. Ed. J. B. Summer. New York: Academic Press.

Pethica, B. A. (1958). Lysis by physical and chemical methods. J. gen. Microbiol. 18, 473.

Rustigan, R. \& Stuart, C. A. (1945). The biochemical and serological relationships of the organisms of the genus Proteus. J. Bact. 49, 419.

SALton, M. R. J. (1957). The action of lytic agents on the surface structures of the bacterial cell. 2nd int. Conf. Surface Activity (London), 4, 245. London: Butterworths. 